\title{
Effects of pelvic and core strength training on biomechanical risk factors for anterior cruciate ligament injuries
}

\author{
Ana FERRI-CARUANA 1 *, Beatriz PRADES-INSA 1, Pilar SERRA-AÑÓ 2
}

${ }^{1}$ Department of Physical Education and Sport, Faculty of Science of Physical Activity and Sport, University of Valencia, Valencia, Spain; 2Department of Physiotherapy, Faculty of Physiotherapy, University of Valencia, Valencia, Spain

*Corresponding author: Ana Ferri-Caruana, Department of Physical Education and Sport, Faculty of Science of Physical Activity and Sport, University of Valencia, C/Gascó Oliag 3 (Aulario V), 46010 Valencia, Spain. E-mail: ana.maria.ferri@uv.es

\section{ABSTRACT}

BACKGROUND: Little is known about the changes in biomechanical risk factors for an anterior cruciate ligament (ACL) injury after participation in a pelvic and core strength training (PCST) program in female team players.

METHODS: This is a randomized controlled trial for which a total of 29 female soccer players were recruited from a soccer club and split into two groups, namely, experimental group ( $\mathrm{EG}, \mathrm{N} .=18$; mean [SD] age, 17.8 \pm 2.0 years, weight 64.0 [6.6 kg and height $1.7[0.0] \mathrm{m})$ and control group (control, N.=11; mean [SD] age, 16.2 [1.2] years, weight 61.6 [7.3] kg and height 1.7 [0.0] m). The EG participated in an in-season 8-week PCST program (twice/week). Participants in the CG performed their normal training without additional pelvic and core strengthening. Pre- and postintervention knee frontal plane projection angle (FPPA), hip, knee and ankle peak flexion angles and jump height were collected during bilateral and unilateral drop jumps.

RESULTS: PCST significantly reduced FPPA at dynamic landing, in both dominant $\left(-7.1^{\circ}\right)$ and non-dominant lower extremities $\left(-8.01^{\circ}\right)$. Further, this training significantly increased the peak hip $\left(24.43^{\circ}\right)$ and knee flexion angles $\left(14.94^{\circ}\right)$, but not the peak ankle dorsiflexion angle $(\mathrm{P}>0.05)$ which, significantly decreased in the $\mathrm{CG}\left(-3.5^{\circ}\right)$. Following the intervention, EG significantly increased measures obtained for both bilateral $(2.84 \mathrm{~cm})$ and unilateral jumps $(1.33 \mathrm{~cm}$ for the dominant leg and $1.22 \mathrm{~cm}$ for the non-dominant leg $)(\mathrm{P}<0.05)$, not so for $\mathrm{CG}(\mathrm{P}>0.05)$.

CONCLUSIONS: PCST resulted in improvements on ACL injury risk factors and vertical drop jump performance, suggesting that strengthening this body part warrants not only injury prevention, but increases jumping performance.

(Cite this article as: Ferri-Caruana A, Prades-Insa B, Serra-Añó P. Effects of pelvic and core strength training on biomechanical risk factors for anterior cruciate ligament injuries. J Sports Med Phys Fitness 2020;60:000-000. DOI: 10.23736/S0022-4707.20.10552-8)

KEY WORDS: Risk factors; Athletic performance; Women; Soccer.

$\mathrm{S}_{\mathrm{e}}^{\mathrm{o}}$ occer is a multidirectional sport that requires high levels of aerobic capacity, speed, agility, and maximal, as well as explosive-strength. ${ }^{1}$ The incidence of injury in soccer ranges from 2 to 9.4 injuries per 1000 hours of active play. ${ }^{2-4}$ In particular, the incidence of anterior cruciate ligament (ACL) injury ranges from 0.06 to 3.7 per 1000 playing hours; ;, 6 this is a major concern because of the negative impact on the career potential of soccer players. ${ }^{7}$ Injury rate varies according to sex, whereby female soccer players are four to six times more likely to suffer an ACL injury than their male counterparts. ${ }^{8,9}$

ACL injury risk is multifactorial ${ }^{10}$ and involves neuro- muscular, anatomic, hormonal and biomechanical factors. Although many cannot be modified, certain factors, such as neuromuscular and biomechanical control patterns, have been shown to be adjustable through training. ${ }^{11-13}$ Modifiable risk factors of both traumatic and overuse injuries of the knee include:14, 15 decreased hip and knee flexion in landings, strength or motor control asymmetries between non-dominant and dominant leg, lower lumbopelvic strength stability, dynamic valgus and abduction loads or knee frontal plane projection angle at landing.

Lower limb biomechanics during activity have been widely postulated as an important factor in the etiology 
of knee injuries. ${ }^{16-18}$. For example, dynamic knee valgus is the resulting medial collapse of the leg during cutting and landing tasks, resulting in hip adduction and internal rotation, relative medial deviation of the knee and tibial abduction ${ }^{12,} 19$ which, in the presence of quadriceps force, increase both ACL strain and patellofemoral joint stress. . $^{20} 21$ In connection with knee valgus, another modifiable biomechanical alteration is the knee frontal plane projection angle (FPPA).

Increased knee FPPA during drop vertical jump (DVJ), for example, is also considered a risk factor and is often tested in athletes in large-scale screening processes, using two-dimensional (2D) kinematic analysis as a useful tool, being portable, inexpensive and readily available. ${ }^{22-24}$ Thus, devising and implementing training programs combined with screening tests that attempt to address these issues would obviously be looked upon favorably by strength and conditioning coaches and team management. According to Hewett et al., ${ }^{14}$ the increase in dynamic valgus and abduction loads that predict a risk of ACL injury in women are often caused by trunk or core dysfunction.

So far, core stability interventions have been combined with other different approaches (i.e. proprioceptive training, dynamic stabilization and plyometrics with strength training and leg alignment, stretching, strengthening or agility drills) in several injury prevention programs. $23,25-27$ However, little is known about the mechanism underlying successful outcomes obtained from the combination of different methods. To our knowledge, there is only one pilot study ${ }^{28}$ which implemented a core strength program (in capoeira athletes) aimed to establish if core strength training would improve landing mechanics and therefore, reduce ACL injury risk factors in female athletes. Furthermore, the results of specific core training in athletes in terms of improving sport performance has been contradictory. $23-29$

Core stability can be defined as the ability to achieve and sustain control of the trunk and hip regions at rest and during precise movements. ${ }^{29,} 30$ It plays an important role in the transfer of energy and the connection of movements between the lower and upper extremities. ${ }^{31,32}$ Core stability is accomplished through a complex interaction of neuromuscular coordination, proprioception, strength and endurance of the trunk and hip musculature. ${ }^{12,22}$

There is a need to further understand the extent to which pelvic and core strength training (PCST) influences injury risk factors for non-contact ACL injury in female soccer players.

The purpose of this study was to evaluate the effects of pelvic and core strength training on biomechanical risk factors for anterior cruciate ligament injuries both in the dominant and non-dominant leg. We also evaluated the influence of the intervention on jump height performance. We hypothesized that players performing PCST would display a reduced knee FPPA during unilateral landing, and greater hip, knee and ankle peak flexion angles during bilateral landing. Players performing PCST would further increase jump height in both bilateral and unilateral drop jump tests compared to non-PCST players.

\section{Materials and methods \\ Study design and participants}

A randomized controlled trial was conducted to assess the impact of an 8-week core stability and strength program on ACL risk factors and jump performance in adolescent female soccer players. Two teams from a female soccer club were recruited and players were randomly assigned either to an experimental (EG) or control (CG) group by a statistician who was not involved in conducting the study. Specifically, a nonstratified allocation was conducted. He prepared sealed and opaque envelops without distinguishing marks that were opened and a treatment was then offered to the participant. Both teams had similar practice and competition schedules throughout the study, yet none of the players from either team had performed any specific core strength program before participating in this research. All of the participants had at least 5-year experience in competition soccer and competed in similar categories (Spanish U18 and U17, equivalent to 'Youth category'). Players from each team had different soccer coaches, but performed the same technical and tactical training. In addition, all players performed the same strength and conditioning training and shared the same strength and conditioning coach.

The EG group performed the exercise program twice a week before the team's regularly scheduled training practice, while the program was implemented by two experienced members of the research team. Participants were assessed twice, once at baseline and again at the end of the 8 -week training.

\section{Sample size}

Sample size calculation was based on a hypothetical medium size effect (based on Cohen's d) of the intervention on the main outcome, i.e., knee FPPA, accounting for two groups and two measurements (pre and postintervention). A total sample size of 24 individuals was required. This 
TABLE I.-Anthropometric and experience profile of the players.

\begin{tabular}{cccccc}
\hline & N. & Age (years) & Weight $(\mathrm{kg})$ & Height $(\mathrm{m})$ & Practice (years) \\
\hline EG & 16 & $17.5(6.0)$ & $63.2(20.7)$ & $1.7(0.1)$ & $10.0(8.0)$ \\
CG & 10 & $16.0(4.0)$ & $63.2(26.3)$ & $1.7(0.2)$ & $10.0(8.0)$ \\
\hline
\end{tabular}

Data are expressed as median (range).

EG: core training group; $\mathrm{CG}$ : control group.

calculation was conducted using GPower v3 G-Power ${ }^{\circledR}$ (Institute for Experimental Psychology, University of Düsseldorf, Düsseldorf, Germany). ${ }^{33}$ Ultimately, we recruited 29 players and performed a randomized allocation with 16 individuals in the EG to account for dropouts. There were eventually three dropouts in the CG due to injury and therefore the final number of participants was 26 (i.e., 16 in the EG and 10 in the CG). All of them had at least 5 -year experience in competition soccer and played in similar categories (Spanish U18 and U17, equivalent to "Youth category"). Players from each team had different soccer coaches, but performed the same technical and tactical training. In addition, all players performed the same strength and conditioning training and shared the same strength and conditioning coach (Table I).

Exclusion criteria were previous ACL injury, lower extremity surgery within the last year, serious lower extremity injury within the last 6 months (defined as an injury requiring more than 4 weeks away from soccer activity), and previous or current participation in an ACL injury prevention program. Before testing, institutional review board approval was obtained and parents' written informed consent and minors' assent were obtained.

\section{Assessment procedure: DVJ Test}

Participants visited the laboratory for preintervention assessment of DVJ Test performance and height and weight measurement and the same procedure was repeated eight weeks later, upon completion of the intervention. In the latter assessment, participants were scheduled at the same appointment time to avoid the influence of diurnal variation in test performance. ${ }^{34}$

To conduct the test, participants were asked to wear shorts to be marked with white tape in order to determine the landmarks according to previous study designs. 35 The anatomical landmarks were the following: acromioclavicular joint, anterior superior iliac spine, patella, center of the ankle, greater trochanter, lateral surface of the thigh, lateral epicondyle of the femur, lateral surface of the leg, lateral malleolus and fifth metatarsal head. The same rater was responsible for placing the markers on each participant and made sure they neither moved nor became detached from the skin during the performance of body movements (jumping or arm movement).

Before the test started, a standard 5-minute warm-up was performed on a static bicycle (Khronos Basic II, BH Bikes S.A., Álava, Spain). The warm-up was controlled by an evaluator in order to ensure that the stipulated time and intensity levels were met. Each participant was asked to perform three to five practice trials of both tasks. ${ }^{36}$ Once participants were familiarized with the tasks, they were asked to perform three test trials for each task; the sequence of bilateral or unilateral (dominant and non-dominant leg) DVJ task was randomized for each participant. Dominant leg was defined as the leg with which they could kick a ball furthest (22). All players were right-leg dominant.

The players were instructed to put hands on hips (barefoot and without covering the marks) and to drop directly down off the bench on to a mark $40 \mathrm{~cm}$ from the bench, landing on both feet (bilateral jumping) or on one foot (unilateral jumps), and immediately perform a maximum vertical jump. ${ }^{37}$ A 30 -second rest was allowed between repetitions and 1-minute rest between different tasks.

Jumps were not considered for the study if participants jumped rather than dropping down from the box, if they moved their arms or if they clearly lost balance during the test. Further, the unilateral test was not deemed valid when the non-supporting leg touched the ground. These criteria were visually judged by the examiner. ${ }^{38}$ When invalid jumps were performed, the participants were allowed to rest for 1 minute and then repeat the attempt. The first 3 valid jumps for each type (i.e., with two legs, right leg and left leg) were selected and included for further analysis.

DVJ reliability in the analysis of biomechanical variables in young athletes is excellent for the sagittal plane (ICC between sessions $>0.8$ ) and for the frontal plane (ICC between sessions $>0.75$ ). ${ }^{39}$

Kinematic analysis was performed via a two-dimensional (2D) FPPA of knee alignment measured during the bilateral and unilateral DVJ tasks. The reliability, measurement error, and validity of this $2 \mathrm{D}$ analysis has been previously established in comparison with 3D. ${ }^{36}$ For the recording of the test, two digital cameras (Samsung ST66, Samsung, South Korea) were placed, one in the sagittal plane and the other in the frontal plane, on a tripod at a height of $101.6 \mathrm{~cm}$ and at a distance of 3.65 meters from the jump box ( $30 \mathrm{~cm}$ high). Left limb jumps were recorded with the participants' left side of the body facing the camera, right limb jumps were recorded with the participants' right side of the body facing the camera.

Variables obtained for the bilateral DVJ were: i. Peak 


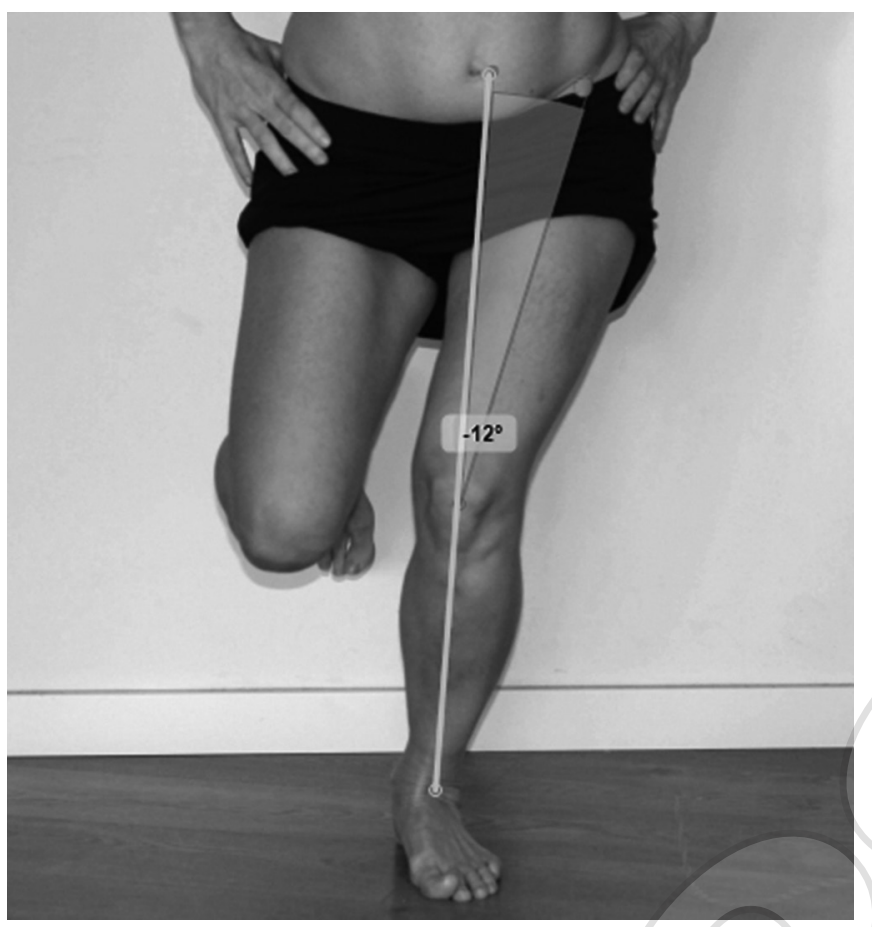

Figure 1.-Knee frontal plane projection angle.

$-12^{\circ}$ knee frontal plane projection angle (FPPA) is formed by lines drawn between the thigh and hip markers and between the ankle and knee markers.

hip and knee flexion, peak ankle dorsiflexion at landing, and total jumping height. For the unilateral DVJ: knee frontal plane projection angle (FPPA) and jumping height $(\mathrm{JH})$ for each leg.

Kinovea sports video and image analysis software (GPLv2 license) was used to analyze jumps and to obtain the variables. Knee FPPA was calculated by measuring the angle formed by lines drawn between the thigh and hip markers and between the ankle and knee markers (Figure 1).

As described by Willson and Davis, 22 from a frontal view, when the knee marker was medial to a line from the ankle marker to the thigh marker, the FPPA was negative. The FPPA was positive if the knee marker was lateral to a line drawn from ankle marker to the thigh marker. Negative knee FPPA values reflected knee valgus, excursion of the knee toward the midline of the body, while positive knee FPPA values reflected varus knee.

The knee FPPA was calculated for each limb at maximum landing knee flexion angle.

The hip flexion angle was the angle between the line formed by the acromioclavicular joint and the greater trochanter, and a second line connecting the greater trochan- ter with the lateral femoral epicondyle. ${ }^{40}$ The knee flexion angle was the angle between the line formed by the greater trochanter and the lateral femoral epicondyle, and a second line connecting the lateral femoral epicondyle and the lateral malleolus. ${ }^{40}$ The ankle dorsiflexion angle was the angle between the line formed by the lateral femoral epicondyle and the lateral malleolus, and a second line connecting the lateral malleolus and fifth metatarsal head. Smaller hip flexion, knee flexion and ankle dorsiflexion angles represent respectively more hip flexion, knee flexion and ankle dorsiflexion.

An electronic timing mat (DIN-A2 Chronojump-Boscosystem, Spain) was placed immediately in front of the jump box to measure flight time as the time between takeoff and ground contact. The chip Chronopic was synchronized with the timing mat during both bilateral and unilateral jumps. Jump height was calculated using the following equation. ${ }^{41,42}$

\section{Jump height $=\left(g \times\right.$ flight time $\left.{ }^{2}\right) 8^{-1}$}

In this equation, $g$ denotes the acceleration of gravity $\left(9.81 \mathrm{~m} / \mathrm{s}^{2}\right)$.

\section{Pelvic and core strength training}

Over the 8-week training period, a total of 16 sessions, each lasting 30 minutes, of pelvic and core strength training were conducted. Exercises were explained by one of the researchers and, for a greater control of the intervention, two trained researchers helped to monitor the proper execution of the exercises (some of them reported in Figure $2,3,4)$. There were 4 strength exercises ( 1 to 4 from

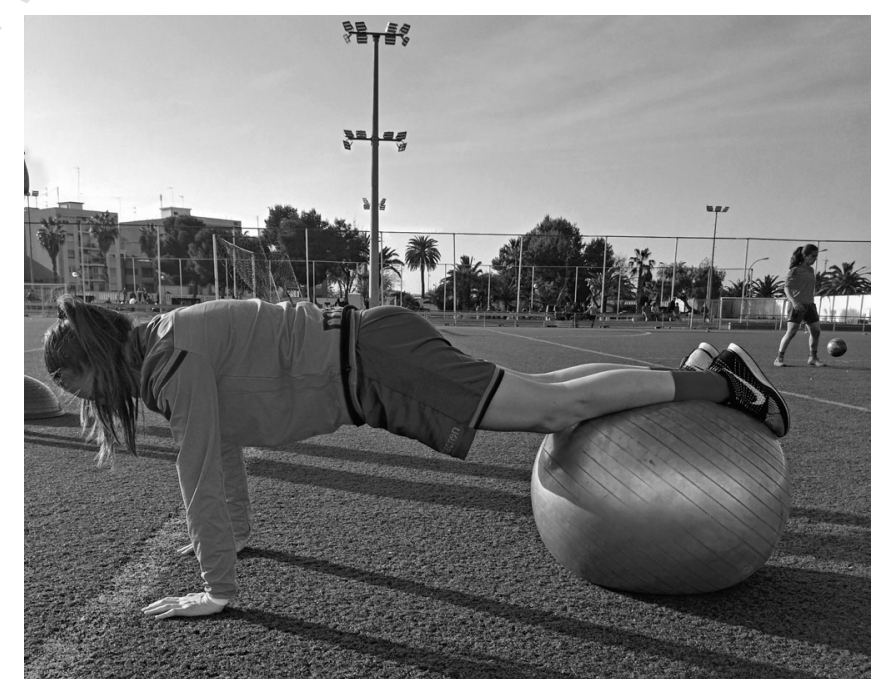

Figure 2.- Swiss ball reverse crunch. 


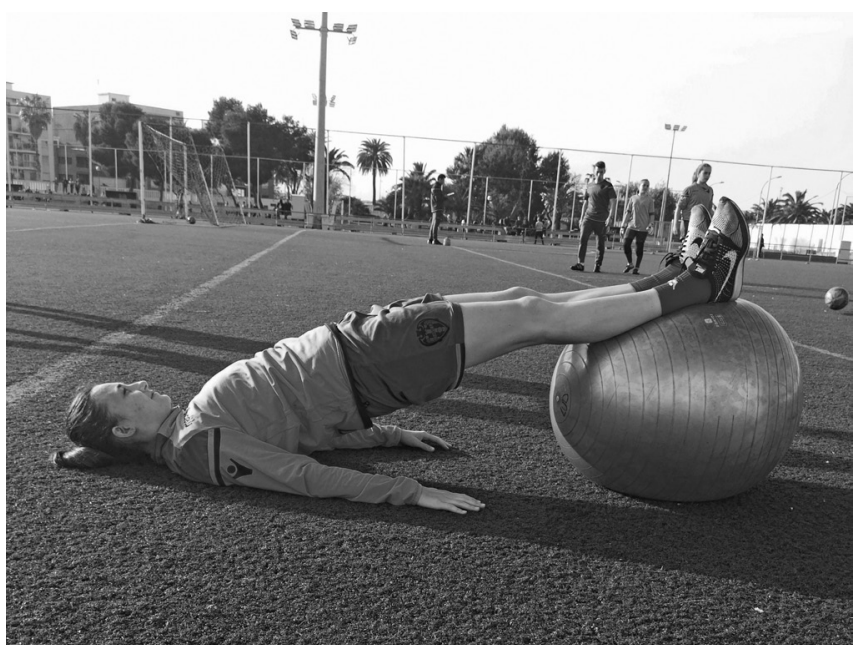

Figure 3.-Bridge with heel digging into Swiss ball.

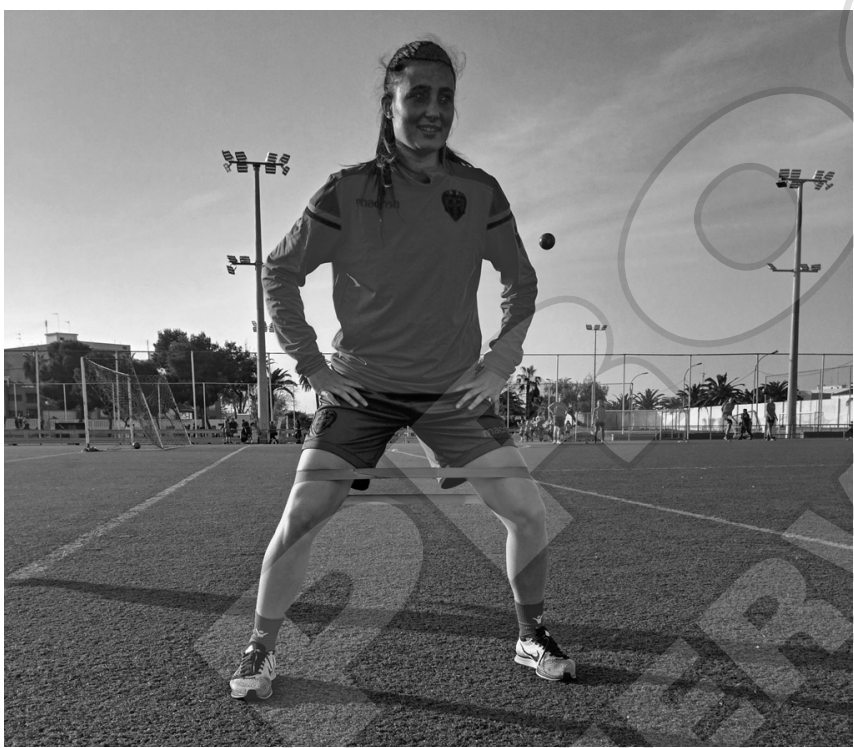

Figure 4.- - Lateral walk with resistance band.
Table II) and 4 stability exercises (5 to 8 from Table II), addressing hip and core muscles, so a set of 8 exercises was performed as a circuit (Table II).

To establish training time and repetitions, we followed the model provided in other similar studies. ${ }^{43,}{ }^{44}$ Due to the difficulty in individualizing exercise intensity in core strength exercises, participants using resistance bands were instructed to do as many repetitions as needed in each set until exertion rated as "very hard" was perceived. The intensity was controlled by the modified 0-10 Borg Scale, ${ }^{45}$ maintaining an intensity between 7 and 8 for each set of exercises. Players who did not experience fatigue after the established training time for isometric contractions were required to add additional weight to ensure fatigue at the end of the exercise. The familiarization session was used to adjust exercise intensity for all players. Subjects' adherence rates were recorded throughout the study period.

Over this 8-week period, CG participants performed 16 sessions of their usual warm-up exercises consisting on active joint mobility, running, dynamic stretching and ball exercises lasting 30 minutes in all.

\section{Statistical analysis}

All data are presented as mean and standard deviation (SD). Assumptions of statistical tests such as normal distribution and homoscedasticity of data were checked, using Shapiro-Wilk test and Levene's test, respectively. Variables for peak hip and knee flexion, peak ankle dorsiflexion and bilateral jump height were analyzed using mixed MANOVA with the between-subject factor group (CG and EG) and the within-subject factor time (pre, post), while FPPA and unilateral jump height were analyzed using another mixed MANOVA with the between-subject factor group (CG and CRG) and two within-subject factors, time (pre, post) and leg dominance (right and left). Significant

TABLE II.-Structure of the 8-week core stability and strength training program.

\begin{tabular}{|c|c|c|c|c|}
\hline \multirow{2}{*}{ Exercise } & \multicolumn{2}{|r|}{ Weeks $1-4$} & \multicolumn{2}{|r|}{ Weeks 4-8 } \\
\hline & Sets & Repetitions & Sets & Repetitions \\
\hline 1) Single-leg standing side trunk flexion with dumbbell (5 and $7.5 \mathrm{~kg}$ ) & 2 & 15 right +15 left & 2 & 20 right +20 left \\
\hline 2) Swiss ball Reverse crunch (Figure 1) & 2 & 20 (bilateral) & 2 & 30 (bilateral) \\
\hline 3) Lateral walk with resistance band (Figure 1) & 2 & 10 right +10 left & 2 & 15 right +15 left \\
\hline 4) Bridge with heels digging into Swiss ball (Figure 1) & 2 & 20 (bilateral) & 2 & 30 (bilateral) \\
\hline 5) Single-leg standing maintaining core stability with hip abduction (resistance band) & 2 & 10 right +10 left & 2 & 15 right +15 left \\
\hline 6) Lying supine contralateral core stability & 2 & 20 reps alternated & 2 & 30 reps alternated \\
\hline 7) Single-leg standing maintaining core stability with leg adduction (resistance band) & 2 & 10 right +10 left & 2 & 15 right +15 left \\
\hline 8) Single-leg standing maintaining core stability with leg kick (resistance band) & 2 & 10 right +10 left & 2 & 15 right +15 left \\
\hline
\end{tabular}

Reps: repetitions 
interactions were followed up with Bonferroni tests. Significance was set at $\mathrm{P}=0.05$. The effect sizes for pairwise comparisons were calculated with Cohen's d. Differences between groups in age, height and weight were checked with the Mann-Whitney U Test (as the normality of the data was not assumed). All data analysis was conducted using SPSS version 23 (SPSS Inc., Chicago, IL, USA).

\section{Results}

\section{Participants}

There was a significant age difference between groups, the $\mathrm{EG}$ being older than the $\mathrm{CG}$ (Mean difference $=1.65$ years). However, both groups were in the same category (Spanish U18 and U17, equivalent to "Youth category"). The height and weight and years of practice were not significantly different between groups $(\mathrm{P}>0.05)$ and there were no differences at baseline in FPPA (dominant and non-dominant), peak hip and knee flexion, peak ankle dorsiflexion and jump height $(\mathrm{P}>0.05)$. None of the 26 participants missed more than one session as required to be included in the analyses. All of them were right-leg dominant.

\section{Effect of the pelvic and core strength intervention}

The interaction between the three factors included in the study showed a tendency to significance $F(2,23)=3.27$, $\mathrm{P}=0.056, \eta^{2}=0.22$. The mean effect of time and dominance were significant, $\mathrm{F}(2,23)=12.28, \mathrm{P}<0.05, \eta^{2}=0.52$ and $\mathrm{F}(2,23)=5.94, \mathrm{P}<0.05, \eta^{2}=0.34$, respectively. The mean effect of group was not significant ( $\mathrm{P}>0.05)$.

In the post-hoc comparisons, Table III reveals that people in the EG showed a significant decrease on the FPPA at landing after PCST, both in their dominant and nondominant leg, as shown in Table III. By contrast, the par-

TABLE III.-Effect of the pelvis and core intervention on frontal plane projection angle for dominant and non-dominant legs during landing after unilateral jumps.

\begin{tabular}{lccc}
\hline FPPA $\left({ }^{\circ}\right)$ & Preintervention & Postintervention & $\mathrm{d}$ \\
\hline Dominant & & & \\
CG & $13.04(5.54)$ & $12.35(8.76)$ & - \\
EG & $12.69(5.81)$ & $5.59(7.22)^{*}$ & 0.69 \\
Non-dominant & & & \\
CG & $10.41(9.10)$ & $8.42(8.60)$ & - \\
EG & $7.43(7.11)$ & $-0.58(8.52)^{*}$ & 0.96 \\
\hline
\end{tabular}

Data are shown as mean (SD).

CG: control group, composed of 10 people; EG: pelvic and core training group, composed of 16 people.

*Significant differences between postintervention and preintervention measurements $(\mathrm{P}<0.05)$.
TABLE IV.-Effect of the pelvic and core intervention on peak hip flexion, knee flexion and ankle dorsiflexion angles at landing after bilateral jumps.

\begin{tabular}{lrcc}
\hline & Preintervention & Postintervention & $\mathrm{d}$ \\
\hline Peak hip flexion angle $\left(^{\circ}\right)$ & & & \\
CG & $79.2(19.99)$ & $83.2(19.44)$ & - \\
EG & $65.13(24.98)$ & $89.56(15.15)^{*}$ & 1.27 \\
Peak knee flexion angle $\left(^{\circ}\right)$ & & & \\
CG & $81.9(11.93)$ & $81.4(9.09)$ & - \\
EG & $74.75(13.75)$ & $89.69(10.64)^{*}$ & 1.27 \\
Peak ankle dorsiflexion angle $\left(^{\circ}\right)$ & & & \\
CG & $86.1(6.64)$ & $82.6(5.06)^{*}$ & 0.59 \\
EG & $88.63(4.44)$ & $87.31(4.41)$ & - \\
\hline
\end{tabular}

Data are shown as mean (SD).

CG: control group, composed of 10 people; EG: core training group, composed of 16 people. *Significant differences between postintervention and preintervention measurements $(\mathrm{P}<0.05)$.

TABLE V.-Effect of the core intervention on the height of the unilateral and bilateral drop vertical jumps.

\begin{tabular}{lllc}
\hline & Preintervention & Postintervention & $\mathrm{d}$ \\
\hline Unilateral JH $(\mathrm{cm})$ & & & \\
Dominant & $11.44(2.17)$ & $12.29(1.4)$ & - \\
CG & $10.42(2.52)$ & $11.75(2.12)^{*}$ & 0.57 \\
$\quad$ EG & $11.83(2.43)$ & $11.02(1.92)$ & - \\
$\quad$ Non-dominant & & & \\
CG & $10.83(2.84)$ & $12.04(2.44)^{*}$ & 0.46 \\
EG & & & \\
Bilateral JH (cm) & $20.54(3.16)$ & $21.30(3.29)$ & - \\
CG & $19.33(4.73)$ & $22.17(3.42)^{*}$ & 0.69 \\
EG & & & \\
\hline
\end{tabular}

Data are shown as mean (SD).

CG: control group, composed of 10 people; EG: pelvic and core training group, composed of 16 people; JH: jump height.

*Significant differences between postintervention and preintervention measurements $(\mathrm{P}<0.05)$.

ticipants not enrolled in this intervention failed to improve their FPPA $(\mathrm{P}>0.05)$.

EG also improved range of motion (ROM)-related variables, namely peak hip and knee flexion angles, not however the peak ankle dorsiflexion angle $(\mathrm{P}>0.05)$, which dropped in the CG (Table IV).

Jump height also improved significantly following the PCST, both when performed with the dominant and nondominant leg, and bilaterally (Table V).

\section{Discussion}

This is a randomized controlled trial that studied the effect of PCST on biomechanical risk factors for ACL injury in female soccer teams. Our results demonstrated a decreased FPPA during unilateral vertical drop jumps (for both legs) and an increased peak hip and knee flexion during bilateral 
vertical drop jumps as a result of the PCST. However, ankle dorsiflexion remained similar for the EG but dropped significantly in the CG. Moreover, PCST improved bilateral jumping height and unilateral jumping for dominant and non-dominant legs.

Consistent with the results of a core stability training program in high school female athletes, ${ }^{44}$ this study reported that by strengthening this part of the body, FPPA was reduced during DVJ. We obtained a reduction of the FPPA in both the dominant leg (mean difference of $6.2^{\circ}$ ) and in the non-dominant leg (mean difference of $8.1^{\circ}$ ). These reductions were greater than those reported by Brown et $a l .{ }^{46}$ on knee valgus angles after applying different neuromuscular-based ACL injury prevention protocols, possibly due to two reasons. First, because they failed to implement a specific gluteus medius strength exercise as we did using exercises such as "Lateral walk with resistance band." Gluteus medius exercises have been shown to reduce knee valgus during dynamic activities and therefore, during landing. The second reason is related to the proper control of the core intervention training since, according to their study limitations, these may have stemmed from a lack of expertise of the assistant training staff.

With respect to flexion, our core intervention group achieved a significant increase in peak hip $\left(24.4^{\circ}\right)$ and knee $\left(14.9^{\circ}\right)$ flexion, which has been related with lowered risk factors for ACL injury. ${ }^{47}$ These results are very similar to those from other studies applying other injury prevention programs. 26,46 However, our results differ from the study carried out by Pfile et al. ${ }^{48}$ who found a decreased knee flexion angle and a decreased hip flexion moment after the core stability training. This discrepancy between results might be due, in addition to their small sample size $(\mathrm{N} .=8)$, to the fact that the exercises were conducted mostly in a frontal and transverse plane, unlike ours that also included exercises in a sagittal plane, and to the fact that it was monitored by coaching staff rather than a qualified clinician. Furthermore, in our study, training was handled by two experienced team professionals: a physiotherapist and a strength and conditioning coach.

The results for peak ankle dorsiflexion, however, failed to confirm our hypothesis, since dorsiflexion did not improve after PCST $(\mathrm{P}>0.05)$. On the other hand, the $\mathrm{CG}$ showed a reduction in peak ankle dorsiflexion $\left(-3.5^{\circ}\right)$. Greater dorsiflexion is associated with reduced ACL injury risk because of the reduced forces to be absorbed by the lower extremity at landing. ${ }^{13}$ Our study disclosed benefits for the knee and hip joints, increasing their contribution peak flexion, not however for ankle dorsiflexion.
This could be due to the fact that the intervention was focused on strengthening and not on the extensibility of certain muscle groups that allow this movement, such as the plantar-flexor muscles. ${ }^{49}$ As our main goal was to establish the benefits of core strengthening, we designed a specific intervention with no further approaches that might conceal the effects. However, combined strategies adding muscle stretching or strengthening of the distal muscles could improve the benefits obtained with the proposed core intervention. Notwithstanding, these results should be taken with caution, since the CG was ultimately composed of 10 people instead of 13 as required, therefore, the small sample size could cause a type 2 error.

Lastly, the EG significantly improved jump height in bilateral jumps $(2.84 \mathrm{~cm})$ and in unilateral jumps, with differences of $1.33 \mathrm{~cm}$ for the dominant leg and of $1.21 \mathrm{~cm}$ for the non-dominant leg. This finding is in line with that reported by Afyon et al., ${ }^{43}$ Taskin et al. ${ }^{44}$ and Hoshikawa et al. 50 that affirm that the combination of core stability/ strength training and regular soccer training improves vertical jumping.

A strong and stable core allows to generate and transmit power to the entire kinetic chain. Many muscles originate in the spine and pelvis, therefore, their strengthening provides a good base to perform more powerful, efficient and stable movements and therefore improve performance. ${ }^{51}$

\section{Limitations of the study}

One limitation of the study was the absence of measures such as reaction forces and muscle activation during tests. Their analysis may provide further insight into the current benefits of core strength training and should be explored in future studies.

Furthermore, it would be interesting to study which specific core training, either muscle stability or muscle strength, reduces ACL risk factors to a greater extent and more greatly affects performance factors. Participants in our study were not accustomed to performing core stability and strength exercises, which might represent a larger stimulus compared to people familiarized with this type of exercise; accordingly, it might be useful to explore the results of a core intervention in trained individuals.

\section{Conclusions}

The results of this study show that the implementation of an in-season, 8-week PCST program for female soccer players leads to improvements related to ACL injury risk factors, such as peak hip and knee flexion angles and 
FPPA during drop jump landing. In addition, it has also been shown to improve jumping height, in bilateral and unilateral jumps.

Future injury prevention efforts in young female soccer players should include core specific strength exercises, because this positively contributes to different biomechanical adaptations.

\section{References}

1. Stølen T, Chamari K, Castagna C, Wisløff U. Physiology of soccer: an update. Sports Med 2005;35:501-36.

2. Ekstrand J, Hägglund M, Waldén M. Injury incidence and injury patterns in professional football: the UEFA injury study. Br J Sports Med 2011;45:553-8.

3. Llana Belloch S, Pérez Soriano P, Lledó Figueres E. La epidemiologia en el fútbol: una revisión sistemática. Rev Int Med Cienc Act Física Deporte 2010;10

4. Stubbe JH, van Beijsterveldt AM, van der Knaap S, Stege J, Verhagen EA, van Mechelen W, et al. Injuries in professional male soccer players in the Netherlands: a prospective cohort study. J Athl Train 2015;50:211-6.

5. Bjordal JM, Arnły F, Hannestad B, Strand T. Epidemiology of anterior cruciate ligament injuries in soccer. Am J Sports Med 1997;25:341-5.

6. Faunø P, Wulff Jakobsen B. Mechanism of anterior cruciate ligament injuries in soccer. Int J Sports Med 2006;27:75-9.

7. Brophy RH, Schmitz L, Wright RW, Dunn WR, Parker RD, Andrish $\mathrm{JT}$, et al. Return to play and future ACL injury risk after ACL reconstruction in soccer athletes from the Multicenter Orthopaedic Outcomes Network (MOON) group. Am J Sports Med 2012;40:2517-22.

8. Agel J, Arendt EA, Bershadsky B. Anterior cruciate ligament injury in national collegiate athletic association basketball and soccer: a 13-year review. Am J Sports Med 2005;33:524-30.

9. Mihata LC, Beutler AI, Boden BP. Comparing the incidence of anterior cruciate ligament injury in collegiate lacrosse, soccer, and basketball players: implications for anterior cruciate ligament mechanism and prevention. Am J Sports Med 2006;34:899-904.

10. Hewett TE, Myer GD, Ford KR. Anterior cruciate ligament injuries in female athletes: Part 1, mechanisms and risk factors. Am J Sports Med 2006;34:299-311.

11. Lephart SM, Abt JP, Ferris CM, Sell TC, Nagai T, Myers JB, et al. Neuromuscular and biomechanical characteristic changes in high schoo athletes: a plyometric versus basic resistance program. Br J Sports Med 2005;39:932-8

12. Pollard CD, Sigward SM, Ota S, Langford K, Powers CM. The influence of in-season injury prevention training on lower-extremity kinematics during landing in female soccer players. Clin J Sport Med 2006;16:223-7. 13. Chappell JD, Limpisvasti O. Effect of a neuromuscular training program on the kinetics and kinematics of jumping tasks. Am J Sports Med 2008;36:1081-6.

14. Hewett TE, Ford KR, Hoogenboom BJ, Myer GD. Understanding and preventing acl injuries: current biomechanical and epidemiologic considerations - update 2010. N Am J Sports Phys Ther 2010;5:234-51.

15. Sigward SM, Pollard CD, Powers CM. The influence of sex and maturation on landing biomechanics: implications for anterior cruciate ligament injury. Scand J Med Sci Sports 2012;22:502-9.

16. Powers CM. The influence of abnormal hip mechanics on knee injury: a biomechanical perspective. J Orthop Sports Phys Ther 2010;40:42-51.

17. Ayala F, De Ste Croix M, Sainz de Baranda P, Santonja F. Intersession reliability and sex-related differences in hamstrings total reaction time, pre-motor time and motor time during eccentric isokinetic contractions in recreational athlete. J Electromyogr Kinesiol 2014;24:200-6.

18. Brent JL, Myer GD, Ford KR, Paterno MV, Hewett TE. The effect of sex and age on isokinetic hip-abduction torques. J Sport Rehabil 2013;22:41-6.

19. Paz GA, Maia MF, Farias D, Santana H, Miranda H, Lima V, et al. Kinematic analysis of knee valgus during drop vertical jump and forward step-up in young basketball players. Int J Sports Phys Ther 2016;11:212-

20. Markolf KL, Willems MJ, Jackson SR, Finerman GA. In situ calibration of miniature sensors implanted into the anterior cruciate ligament part I: strain measurements. J Orthop Res 1998;16:455-63.

21. Lee TQ, Morris G, Csintalan RP. The influence of tibial and femoral rotation on patellofemoral contact area and pressure. J Orthop Sports Phys Ther 2003;33:686-93.

22. Willson JD, Davis IS. Utility of the frontal plane projection angle in females with patellofemoral pain. J Orthop Sports Phys Ther 2008;38:606-15.

23. Noyes FR, Barber-Westin SD, Tutalo Smith ST, Campbell T. A training program to improve neuromuscular and performance indices in female high school soccer players. J Strength Cond Res 2013;27:340-51.

24. McLean SG, Walker K, Ford KR, Myer GD, Hewett TE, van den Bogert AJ. Evaluation of a two dimensional analysis method as a screening and evaluation tool for anterior cruciate ligament injury. Br J Sports Med 2005;39:355-62.

25. van Beijsterveldt AM, van de Port IG, Krist MR, Schmikli SL, Stubbe $\mathrm{JH}$, Frederiks JE, et al. Effectiveness of an injury prevention programme for adult male amateur soccer players: a cluster-randomised controlled trial. Br J Sports Med 2012;46:1114-8.

26. Thompson JA, Tran AA, Gatewood CT, Shultz R, Silder A, Delp SL, et al. Biomechanical effects of an injury prevention program in preadolescent female soccer athletes. Am J Sports Med 2017;45:294-301.

27. Gilchrist J, Mandelbaum BR, Melancon H, Ryan GW, Silvers HJ, Griffin LY, et al. A randomized controlled trial to prevent noncontact anterior cruciate ligament injury in female collegiate soccer players. Am J Sports Med 2008;36:1476-83.

28. Araujo S, Cohen D, Hayes L. Six weeks of core stability training improves landing kinetics among female capoeira athletes: a pilot study. J Hum Kinet 2015;45:27-37.

29. Huxel Bliven $\mathrm{KC}$, Anderson BE. Core stability training for injury prevention. Sports Health 2013;5:514-22.

30. Majewski-Schrage T, Evans TA, Ragan B. Development of a corestability model: a delphi approach. J Sport Rehabil 2014;23:95-106.

31. Kubo T, Hoshikawa Y, Muramatsu M, Iida T, Komori S, Shibukawa $\mathrm{K}$, et al. Contribution of trunk muscularity on sprint run. Int J Sports Med 2011;32:223-8.

32. Hibbs AE, Thompson KG, French D, Wrigley A, Spears I. Optimizing performance by improving core stability and core strength. Sports Med 2008;38:995-1008

33. Hewett TE, Lindenfeld TN, Riccobene JV, Noyes FR. The effect of neuromuscular training on the incidence of knee injury in female athletes. A prospective study. Am J Sports Med 1999;27:699-706.

34. Knaier R, Infanger D, Cajochen C, Schmidt-Trucksaess A, Faude $\mathrm{O}$, Roth R. Diurnal and day-to-day variations in isometric and isokinetic strength. Chronobiol Int 2019;36:1537-49.

35. Dingenen B, Malfait B, Nijs S, Peers KH, Vereecken S, Verschueren $\mathrm{SM}$, et al. Can two-dimensional video analysis during single-leg drop vertical jumps help identify non-contact knee injury risk? A one-year prospective study. Clin Biomech (Bristol, Avon) 2015;30:781-7.

36. Munro A, Herrington L, Carolan M. Reliability of 2-dimensional video assessment of frontal-plane dynamic knee valgus during common athletic screening tasks. J Sport Rehabil 2012;21:7-11.

37. Herrington L. Knee valgus angle during landing tasks in female volleyball and basketball players. J Strength Cond Res 2011;25:262-6. 
38. Malfait B, Sankey S, Firhad Raja Azidin RM, Deschamps K, Vanrenterghem J, Robinson MA, et al. How reliable are lower-limb kinematics and kinetics during a drop vertical jump? Med Sci Sports Exerc 2014;46:678-85.

39. Ford KR, Myer GD, Hewett TE. Reliability of landing 3D motion analysis: implications for longitudinal analyses. Med Sci Sports Exerc 2007;39:2021-8.

40. Norris BS, Olson SL. Concurrent validity and reliability of two-dimensional video analysis of hip and knee joint motion during mechanical lifting. Physiother Theory Pract 2011;27:521-30.

41. García-López J, Peleteiro J, Rodgríguez-Marroyo JA, Morante JC, Herrero JA, Villa JG. The validation of a new method that measures contact and flight times during vertical jump. Int J Sports Med 2005;26:294-302.

42. Tauchi K, Endo T, Ogata M, Matsuo A, Iso S. The characteristics of jump ability in elite adolescent athletes and healthy males: the development of countermovement and rebound jump ability. Int J Sport Health Sci 2008;6:78-84.

43. Afyon YA. Effect of core training on 16 year-old soccer players. Educ Res Rev 2014;9:1275.

44. Taskin C. Effect of Core Training Program on Physical Functional Performance in Female Soccer Players. Int Educ Stud 2016;9:115.
45. Borg GA. Psychophysical bases of perceived exertion. Med Sci Sports Exerc 1982;14:377-81.

46. Brown TN, Palmieri-Smith RM, McLean SG. Comparative adaptations of lower limb biomechanics during unilateral and bilateral landings after different neuromuscular-based ACL injury prevention protocols. J Strength Cond Res 2014;28:2859-71.

47. Griffin LY, Agel J, Albohm MJ, Arendt EA, Dick RW, Garrett WE, et al. Noncontact anterior cruciate ligament injuries: risk factors and prevention strategies. J Am Acad Orthop Surg 2000;8:141-50.

48. Pfile KR, Hart JM, Herman DC, Hertel J, Kerrigan DC, Ingersoll CD. Different exercise training interventions and drop-landing biomechanics in high school female athletes. J Athl Train 2013;48:450-62.

49. Fong CM, Blackburn JT, Norcross MF, McGrath M, Padua DA. Ankle-dorsiflexion range of motion and landing biomechanics. J Athl Train 2011;46:5-10.

50. Hoshikawa Y, Iida T, Muramatsu M, Ii N, Nakajima Y, Chumank $\mathrm{K}$, et al. Effects of stabilization training on trunk muscularity and physical performances in youth soccer players. J Strength Cond Res 2013;27:3142-9.

51. Handzel TM. Core training for improved performance. NSCA's Perform Train J. 2003;2:26-30.

Conflicts of interest.-The authors certify that there is no conflict of interest with any financial organization regarding the material discussed in the manuscript. History.-Article first published online: . - Manuscript accepted: . - Manuscript revised: . - Manuscript received: 